\title{
INFLUENCE OF OBESITY ON BONE MINERAL DENSITY IN POSTMENOPAUSAL ASTHMA PATIENTS UNDERGOING TREATMENT WITH INHALED CORTICOSTEROIDS
}

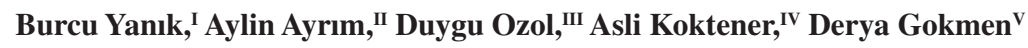 \\ doi: 10.1590/S1807-59322009000400008
}

\begin{abstract}
Yanık B, Ayrım A, Ozol D, Koktener A, Gokmen D. Influence of obesity on bone mineral density in postmenopausal asthma patients undergoing treatment with inhaled corticosteroids. Clinics. 2009;64(4):313-8.
\end{abstract}

OBJECTIVES: The etiology of osteoporosis in asthma is complex as various factors contribute to its pathogenesis. The purpose of our study was to investigate the effects of obesity and inhaled steroids, as well as the severity and duration of asthma, on osteoporosis in postmenopausal asthma patients as compared to healthy controls.

METHODS: A total of 46 patients with asthma and 60 healthy female controls, all postmenopausal, were enrolled in our study. Bone mineral density was assessed at the lumbar spine and hip using a Lunar DPX-L densitometer.

RESULTS: Bone mineral density (BMD) scores were comparable between the asthmatic and control groups, with average scores of $0.95 \pm 0.29$ and $0.88 \pm 0.14 \mathrm{~g} / \mathrm{cm}^{2}$, respectively. Likewise, osteoporosis was diagnosed in a similar percentage of patients in the asthmatic $(39.1 \%)$ and control $(43.3 \%)$ groups. Bone fracture was identified in four patients with asthma (8.6\%) and in six patients from the control group (10\%). We could not detect any relationship between BMD and duration of asthma, asthma severity, inhaled steroids or body mass index (BMI). There was no difference between the two groups with respect to age or years since menopause. Although asthma patients were more likely to be overweight and presented higher BMD scores on average than the control subjects, these differences were not statistically significant.

CONCLUSIONS: There is a slight positive protective effect of high BMI against osteoporosis in asthma patients, but this effect is overcome by time and menopause status. Therefore, the protective effect of obesity against osteoporosis in asthma patients seems to not be significant.

KEYWORDS: Asthma; Obesity; Osteoporosis; Bone mineral densitometry; Inhaled steroids.

\section{INTRODUCTION}

Osteoporosis is a systemic skeletal disease that leads to an increased risk of fracture as a result of a reduction in the

\footnotetext{
${ }^{\text {I }}$ Department of Physical Therapy and Rehabilitation, Fatih University Faculty of Medicine - Ankara, Turkey.

II Department of Obstetrics and Gynecology, Fatih University Faculty of Medicine - Ankara, Turkey.

III Department of Pulmonology, Fatih University Faculty of Medicine - Ankara, Turkey.

IV Department of Radiology, Fatih University Faculty of Medicine - Ankara, Turkey.

${ }^{\mathrm{v}}$ Department of Biostatistics, Ankara University Faculty of Medicine - Ankara, Turkey.

Email: dozol@hotmail.com

Phone: 00905324439693

Received for publication on November 05,2008

Accepted for publication on January 06, 2009
}

amount of normally mineralized bone and deterioration in the microarchitectural bone tissue and trabecular elements. Bone mineral density (BMD) is the major measurable determinant of the risk for osteoporotic fracture. ${ }^{1}$ Obesity has a protective effect on bone metabolism while menopause is associated with a negative imbalance in bone metabolism. ${ }^{2,3}$

Asthma is a chronic inflammatory disease of the airways with an estimated 300 million cases worldwide and is a significant cause of morbidity that is associated with reduced quality of life. Inhaled corticosteroids (ICS) are the most effective anti-inflammatory medication for the treatment of persistent asthma, with fewer side effects than oral corticosteroids. Although the increasing use of moderate and high doses of ICS over the long term has the potential to cause systemic side effects by suppression 
of the hypothalamic-pituitary-adrenal axis, regular use of inhaled steroids reduces the need for oral steroid therapy ${ }^{4}$. Both Egan $^{5}$ and Kaye ${ }^{6}$ found that taking ICS for more than 24 months had no significant effect on BMD. On the other hand, McDonalds ${ }^{7}$ and Israel $^{8}$ showed that ICS usage can lead to bone loss. In most studies, confounding factors such as age, menopausal status, physical activity, body weight and BMI were not adequately taken into account. The effects of ICS on bone mineral density are therefore not clear and the appropriateness of this treatment regimen for osteoporotic asthmatic patients remains questionable.

Coexistent osteoporosis was found to be a significant factor in negatively impacting the quality of life of asthma sufferers. ${ }^{9}$ Additionally, thoracic vertebral fractures can cause further impairment to lung function and Kado ${ }^{10}$ reported increased mortality in elderly women with vertebral fractures. Osteoporosis is thus a very important consideration for asthma patients.

The relationship between obesity and asthma has been widely studied and epidemiological evidence shows that the prevalence of each condition is increasing worldwide. The purpose of our study was to determine the effects of inhaled steroids and obesity, as well as asthma duration and severity, on osteoporosis in postmenopausal asthma patients.

\section{MATERIALS AND METHODS}

\section{Subjects}

A total of 46 patients who presented with asthma as defined by GINA (The Global Initiative for Asthma) ${ }^{11}$ criteria were enrolled in this study from the pulmonology outpatient clinic at our facility. All patients were postmenopausal. Respiratory symptoms, medications and years since menopause were assessed in detail and pulmonary function tests were performed in a standard fashion using an electronic spirometer (MIR) for every subject. Each patient had to complete at least three forced vital capacity (FVC) maneuvers, the best of which was selected as directed by the European Respiratory Society. According to the results of the spirometer test, clinical asthma symptomatology and usage of medications, especially doses of inhaled corticosteroids, asthma patients were classified into three groups of increasing asthma severity according to GINA. Patient characteristics such as duration of asthma and ICS details (type of drugs, prescribed doses, compliance as estimated from questionnaire data, duration, and number of short courses of systemic steroids) were recorded. The ICS medications used by our cohort included beclametasone dipropionate (BDP), fluticasone proprionate (FP) or budesonide. The duration of use of each type of steroid inhaler as well as the mean daily and cumulative doses were determined from the patients' medical diaries and expressed in terms of the equipotent dose of BDP in micrograms $(\mu \mathrm{g})$ by a respiratory medicine specialist. Patients who had a history of continuous systemic corticosteroid use for more than one week during recent years were excluded from our study. Only those patients who had regularly taken ICS for at least 12 months were included in our study.

A total of 60 healthy female postmenopausal subjects were enrolled in this study as a control group. All of the subjects were asked in detail about their asthma and pulmonary function tests were performed in ambiguous cases. Exclusion criteria for the study included a history of hypothyroidism, hyperthyroidism, diabetes, use of drugs that affect bone metabolism, and any other endocrine or inflammatory diseases that can affect body weight or bone metabolism. The daily physical activity and dietary habits of each patient were recorded. A validated food frequency questionnaire (FFQ) ${ }^{12}$ containing 15 items that identifies the frequencies and portion sizes of consumed common food items in order to estimate daily calcium intake was completed by all patients. Only those who consumed 500-750 mg calcium daily were included in the study. Patients taking calcium supplements, osteoporosis medicine or any other medication likely to affect skeletal metabolism, such as sexual steroids, anticoagulants and anticonvulsive drugs, were not included in the study.

\section{Body mass index}

Each participant's height and weight were measured by the same individual using the same equipment. Weight was measured using a calibrated hospital scale with subjects dressed in normal indoor clothing but without wearing shoes. Height was measured in centimeters using a fixed tape measure with subjects standing shoeless on a hard surface against a wall. Body mass index was calculated by dividing body weight by height squared $\left(\mathrm{kg} / \mathrm{m}^{2}\right)$. Patients were evaluated in three groups according to their BMI: BMI $\leq 25$ (normal, group 1), BMI between 25.1 and 29.9 (overweight, group 2) and $\mathrm{BMI} \geq 30$ (obese, group 3 ).

\section{Bone densitometry}

Bone mineral density $\left(\mathrm{g} / \mathrm{cm}^{2}\right)$ was assessed by dual energy X-ray absorptiometry at the lumbar spine and hip (femoral neck and trochanter) using a Lunar DPX-L densitometer (Lunar Radiation; Madison WI). BMD is expressed as the standard deviation (SD) of means, T-score and Z-score. The Z-score is a SD from age- and sex-adjusted average BMD and the T- score is a SD from a young adult sex-matched control population. All scans were analyzed 
by the same doctor. The coefficient of variation was $0.5 \%$ with Phanton and $2 \%$ for the in vivo evaluation. Accuracy and precision were $1 \%$ and $2 \%$, respectively. Osteoporosis was diagnosed according to the criteria of the World Health Organization (WHO) as a BMD of $>2.5$ SD units below the mean for young adults. Osteopenia is in turn defined as a BMD between 1 and 2.5 SD units below the mean BMD for young adults (i.e., the T-score).$^{13}$ All patients were asked to provide a history of doctor-diagnosed bone fractures (especially hip and vertebral breakages). Fractures with relevant clinical symptoms as well as those that occurred as a result of minor trauma were included. Fractures following severe trauma, like falling from greater than standing height or a traffic accident, were excluded.

\section{Statistics}

All results were expressed as means $\pm \mathrm{SD}$. The significance of differences between groups was assessed using the unpaired Student's t-test or Mann Whitney U tests for continuous variables. The chi-square test or Fischer's Exact test was used to test prevalence between groups. Pearson simple linear regression and correlation analyses were used to evaluate the interrelationships between parameters. In addition, regression analysis was used to assess the association between bone density and age, body mass, years since menopause, and asthma severity. The statistical analysis was performed using the SPSS-11 program and $p$ values $<0.05$ were considered significant.

\section{RESULTS}

A total of 46 patients presenting asthma as described by GINA and 60 healthy female controls, all postmenopausal, were enrolled in this study. There was no difference between the two groups with regard to age, race, smoking habits or years since menopause (Table 1). No patients were taking any medication for osteoporosis. All patients had a normal daily dietary calcium intake and all consumed similar amounts of milk and milk products according to their food frequency questionnaires (673.7 mg vs. $684.5 \mathrm{mg}$ calcium daily for asthma and control groups, respectively). Although none of the women had regular exercise routines, they all maintained fully ambulatory, independent, active life-styles tailored to their jobs and daily activities. Although asthma patients were more likely to be overweight or obese, this difference was not statistically significant.

Among 42 of the asthma patients, 21 used budesonide, 17 used FP and the others were on BDP. Characteristics of asthma patients, severity classifications according to GINA and details of ICS medication are shown in Table 2.
Table 1 - Demographic characteristics of patients in this study

\begin{tabular}{llll}
\hline & Asthma & Control & $\mathrm{p}$ \\
\hline Age (years) & $62.5 \pm 10.6$ & $63.0 \pm 6.1$ & 0.561 \\
Years since menopause & $5.6 \pm 1.2$ & $6.5 \pm 1.9$ & 0.198 \\
Race, gender & White, females & White, females & \\
Body mass index & $28.4 \pm 5.1$ & $26.4 \pm 4.6$ & 0.078 \\
$\quad$ Height (cm) & $155.5 \pm 3.59$ & $158.0 \pm 4.3$ & 0.037 \\
$\quad$ Weight (kg) & $69.2 \pm 7.2$ & $67.3 \pm 7.7$ & 0.465 \\
BMI n (\%) & & & 0.677 \\
$\quad$ Normal & $9(19.6)$ & $21(35)$ & \\
$\quad \begin{array}{l}\text { Overweight } \\
\text { Obese }\end{array}$ & $23(50)$ & $22(36.7)$ & \\
Smoking Habits n $(\%)$ & $14(30.4)$ & $17(28.3)$ & \\
$\quad$ Current smoker & $4(8.7)$ & $6(10)$ & 0.356 \\
$\quad \begin{array}{l}\text { Never smoked } \\
\text { Quit smoking }\end{array}$ & $6(13)$ & $68(80)$ & \\
\hline
\end{tabular}

BMI: Bone mineral index

Table 2 - Asthma-related parameters and pulmonary function test values for asthma patients

\begin{tabular}{lc}
\hline Variables & Bronchial Asthma \\
\hline Asthma severity (\%) & 42.6 \\
Mild & 33.4 \\
Moderate & 22.5 \\
Severe & $7.8 \pm 7.7$ \\
Duration of asthma (years) & $2017.2 \pm 618.1$ \\
FEV $_{1}(\mathrm{~mL})$ & $83.1 \pm 17.8$ \\
FEV $_{1}(\%$ predicted $)$ & $4.3 \pm 2.6$ \\
Duration of ICS $($ years $)$ & $798.3 \pm 348.1$ \\
Cumulative ICS dose $(\mathrm{mg})$ & $324.9 \pm 121.8$ \\
Daily ICS dose $(\mu \mathrm{g})$ &
\end{tabular}

*Prescribed dose $=$ equivalent dose of beclamethasone $\times$ estimated compliance

Although we found that mean and total T- and Z-scores for both lumbar and femoral regions were lower in control subjects, this difference was not statistically significant. According to the WHO osteoporosis classifications for both lumbar and femoral T-scores, there was no difference between the groups (Table 3). The prevalence rate of bone fracture history was similar between groups. Three patients in the control group had a history of major traumatic vertebral fracture. Atraumatic vertebral fracture was recorded in four patients with asthma (8.6\%) and in six patients from the control group (10\%). None of the subjects reported hip fractures.

The Pearson's correlation analysis revealed no significant correlation between BMD and BMI, weight, duration of asthma, lung function, age, and asthma severity or inhaled steroid usage. As asthma severity increased from the mild to the severe form, mean lumbar T-scores decreased, but this 
Table 3 - Bone mineral densitometer results and osteoporosis classifications

\begin{tabular}{lccc}
\hline Bone data & Asthma & Control & $\mathrm{p}$ \\
\hline Lumbar T score & $-1.7 \pm 1.3$ & $-1.91 \pm 1.1$ & 0.190 \\
Femoral T score & $-1.2 \pm 1.2$ & $-1.47 \pm 0.9$ & 0.173 \\
Total Spine BMD, g/cm ${ }^{2}$ & $0.95 \pm 0.29$ & $0.88 \pm 0.14$ & 0.086 \\
Femoral neck BMD, g/cm & $0.83 \pm 0.12$ & $0.74 \pm 0.23$ & 0.034 \\
BMD Classification* (n) & & & 0.057 \\
Normal & 9 & 8 & \\
Osteopenia & 19 & 26 & \\
Osteoporosis & 18 & 26 & \\
\hline
\end{tabular}

*Diagnosis of osteopenia and osteoporosis was performed according to $\mathrm{T}$-score values. All values are presented as mean $\pm \mathrm{SD}$, all $\mathrm{p}$ values $>0.05$

was not significant. For asthma patients, mean body weights were $65.2,68.6$ and $73.5 \mathrm{~kg}$ for osteoporotic, osteopenic and normal patients, respectively. Although we found a progressive parallel increase in mean body weights and lumbar T-scores, this trend was not statistically significant (Table 4). When the effect of age, years after menopause and BMI were adjusted in the logistic regression analysis, the risk of low BMD was found to be similar to that of the control group.

Table 4 - Relationship between asthma severity, ICS and BMD

\begin{tabular}{lccc}
\hline & $\begin{array}{c}\text { Lumbar spine } \\
\text { T-score }\end{array}$ & $\begin{array}{c}\text { Femoral neck } \\
\text { T-score }\end{array}$ & $\mathrm{p}$ \\
\hline Asthma patients BMI & & & 0.786 \\
$\quad$ Normal & $-1.8 \pm 0.9$ & $\mathbf{- 1 . 6} \pm \mathbf{0 . 8}$ & \\
$\quad$ Overweight & $-1.7 \pm 1.1$ & $\mathbf{- 0 . 8} \pm \mathbf{1 . 1}$ & \\
$\quad$ Obese & $-1.0 \pm 1.4$ & $\mathbf{- 0 . 7 \pm \mathbf { 1 . 1 }}$ & \\
Asthma severity & & & 0.198 \\
$\quad$ Mild & $-1.9 \pm 0.8$ & $-1.2 \pm 1.0$ & \\
$\quad$ Moderate & $-0.9 \pm 1.3$ & $-0.6 \pm 1.1$ & \\
$\quad$ Severe & $-1.5 \pm 1.4$ & $-1.2 \pm 1.2$ & \\
Mean daily dose of inhaled & & & 0.678 \\
steroids & & & \\
$\quad>500$ & $-1.4 \pm 0.9$ & $-1.1 \pm 0.7$ & \\
$\quad \leq 500$ & $-1.7 \pm 1.2$ & $-1.3 \pm 0.9$ & \\
\hline
\end{tabular}

\section{DISCUSSION}

The present study found no relationship between BMD and duration of asthma, lung function, age, asthma severity, use of inhaled steroids or body mass index. A progressive parallel increase in mean body weights and BMD scores was detected, but the relationship was not statistically significant.

The etiology of osteoporosis in obstructive lung diseases is complicated by the fact that various factors contribute to its pathogenesis. Smoking, hypercapnia, chronic inflammation, reduced skeletal muscle mass and changes in body composition can all increase the risk of both osteoporosis and lung disorders. Altered lung function can induce limitations in physical activity due to dyspnoea. ${ }^{14,15}$ $\operatorname{Sin}^{16}$ found that the risk of osteoporosis among males and females was positively correlated with the severity of obstructive disease. Katsura ${ }^{17}$ found that this relationship is more obvious in chronic bronchitis and emphysema patients than in asthmatics. It is unclear whether asthma alone is a risk factor for osteoporosis. Laatikainen ${ }^{18}$ showed that BMD scores of premenopausal asthmatics with no history of corticosteroid use did not differ from those of non-asthmatics. Similarly, in our study we did not find a relationship between asthma-related parameters and BMD, even after controlling for the use of ICS. Most of our patients had mild or moderate persistent asthma and recorded normal scores on the pulmonary function test, suggesting that they suffered no limitations in terms of physical activity. Most of our asthma and control patients denied smoking, while all others had a smoking history of fewer than ten packs/year. The effect of smoking was therefore also negligible.

Obesity has been implicated as an asthma risk factor and has a positive effect on BMD. A meta analysis of prospective epidemiologic studies showed a dose response effect of elevated BMI on asthma incidence for both women and men, with an odds ratio of $1.92,95 \% \mathrm{CI} 1.43-2.59, \mathrm{p}<0.0001 .{ }^{19}$ The positive effect of obesity on bone is multifactorial. Estrogen levels tend to be higher in obese people due to the increased aromatization of testosterone to estrogen in adipose tissue, decreased sex hormone binding globulin that leads to an increase in free sex steroids, increased level of leptin in serum and increased synthesis of insulin-like growth factors in liver and in the skeleton, which each stimulate bone formation. ${ }^{20-21}$ Additionally, the mechanical impact of higher weight-bearing loads has a positive effect on bone mass, with the result that subjects with high BMIs tend to have higher BMD. In our study, we also found that obesity was more common among asthma patients and that mean body weights and BMD scores increased in parallel, but without statistical significance. We concluded that the protective effect of obesity probably decreases over time and with menopause status, which indicates that the effect of obesity on osteoporosis in postmenopausal asthma patients is likely not significant.

ICS have become a key element in the treatment of asthma. These drugs are absorbed through mucosal surfaces into the systemic circulation, but the extent to which they have adverse effects on bone is uncertain. Herrala ${ }^{22}$ found that inhaling $1000 \mu \mathrm{g}$ doses of BDP/day for a one-year period did not affect BMD. A cross-sectional study in postmenopausal women noted no difference in BMD on 
account of cumulative dose of ICS, duration or current dose greater than or less than $1000 \mu \mathrm{g} .{ }^{23}$ On the other hand, Wong ${ }^{24}$ identified a negative correlation between total cumulative dose of ICS and BMD and Hanania ${ }^{25}$ concluded that ICS may affect bone density in a doserelated fashion. The discrepancy between these results might be explained by confounding factors such as age, menopausal status, physical activity, body weight and BMI. Fujita ${ }^{26}$ found that in contrast to premenopausal asthmatic patients, postmenopausal asthmatics presented reduced BMD and decreased bone formation as a consequence of BDP treatment, and concluded that ovarian hormones may be protective against the adverse effects of ICS in the premenopausal stage. Although effects of confounding factors cannot be entirely excluded in a cross-sectional study, we searched for a relation between inhaled steroid dose and duration and BMD using linear regression analysis, accounting for potential confounders such as weight, BMI, exercise, oral steroid use, age and postmenopausal status. Our findings are in agreement with previous data suggesting that inhaled steroid therapy has no detrimental effect on bone density in postmenopausal asthmatic patients. In our study, the prevalence of osteoporosis and osteopenia was also similar between the asthma and control groups. ICS therapy allows patients to control their asthma and thus be able to exercise, which in turn improves BMD and protects against osteoporosis. Another advantage of inhaled steroids is that they reduce the need for oral corticosteroids by improving respiratory function. One potential limitation of our study is that we could not analyze biochemical markers of bone metabolism. These markers, however, have poor reproducibility and seem to be less sensitive for detecting changes than BMD. ${ }^{27}$ In addition, the correlation between laboratory tests and clinical adverse effects is at times negligible, so we preferred to rely upon bone densitometer findings. ${ }^{28}$

Early detection of osteoporosis and therapeutic options for the prevention and management of osteoporosis are especially important for the female postmenopausal population. We found that BMD values of postmenopausal asthma patients were no different from those of control subjects of the same age group who exhibited similar characteristics in terms of other parameters. We conclude that the risk of osteoporosis does not increase for appropriately treated asthma patients and that there is a slight positive protective effect of high BMI against osteoporosis in asthma patients. However, this effect is rendered insignificant by age and years of estradiol deficiency.

\section{REFERENCES}

1. Consensus development conference: diagnosis, prophylaxis, and treatment of osteoporosis. Am J Med. 1993;94:646-50.

2. Zhao LJ, Jiang H, Papasian CJ, Maulik D, Drees B, Hamilton J, et al. Correlation of obesity and osteoporosis: effect of fat mass on the determination of osteoporosis. J Bone Miner Res. 2008;23:17-29.

3. Soyka LA, Fairfield WP, Klibanski A. Clinical review 117: Hormonal determinants and disorders of peak bone mass in children. J Clin Endocrinol Metab. 2000;85:3951-63.

4. Dahl R. Systemic side effects of inhaled corticosteroids in patients with asthma. Respir Med. 2006;100:1307-17.

5. Egan JJ, Maden C, Kalra S, Adams JE, Eastell R, Woodcock AA. A randomized, double-blind study comparing the effects of beclomethasone and fluticasone on bone density over two years. Eur Respir J. 1999;13:1267-75.

6. Kaye TB. Effect of an inhaled glucocorticoid, flunisolide, on bone mineral density: a 2-year prospective, controlled trial. Endocr Pract. 2000;6:311-7.

7. McDonald CF, Zebaze RM, Seeman E. Calcitriol does not prevent bone loss in patients with asthma receiving corticosteroid therapy: a doubleblind placebo-controlled trial. Osteoporos Int. 2006;17:1546-51.

8. Israel E, Banerjee TR, Fitzmaurice GM, Kotlov TV, LaHive K, LeBoff MS. Effects of inhaled glucocorticoids on bone density in premenopausal women. N Engl J Med. 2001;345:941-7.
9. Adams RJ, Wilson DH, Taylor AW, Daly A, Tursan d'Espaignet E, Dal Grande E et al. Coexistent chronic conditions and asthma quality of life: a population-based study. Chest. 2006;129:285-91.

10. Kado DM, Browner WS, Palermo L, Nevitt MC, Genant HK, Cummings SR. Vertebral fractures and mortality in older women: a prospective study. Study of Osteoporotic Fractures Research Group. Arch Intern Med. 1999;159:1215-20.

11. www.ginasthma.com.

12. Clover E, Miller M, Bannerman E, Magarey A. Relative validation of a short food frequency questionnaire to assess calcium intake in older adults. Aust N Z J Public Health. 2007;31:450-8.

13. Hodgson SF, Watts NB, Bilezikian JP, Clarke BL, Gray TK, Harris DW, et al. American Association of Clinical Endocrinologists medical guidelines for clinical practice for the prevention and treatment of postmenopausal osteoporosis: 2001 edition, with selected updates for 2003. Endocr Pract. 2003;9:544-64.

14. Biskobing DM. COPD and osteoporosis. Chest. 2002;121:609-20.

15. Bourjeily G, Rochester CL Exercise training in chronic obstructive pulmonary disease. Clin Chest Med. 2000;21:763-81.

16. Sin DD, Man JP, Man SF. The risk of osteoporosis in Caucasian men and women with obstructive airways disease. Am J Med. 2003;114:10-4. 
17. Katsura H, Kida K. A comparison of bone mineral density in elderly female patients with COPD and bronchial asthma. Chest. 2002;122:194955 .

18. Laatikainen AK, Kröger HP, Tukiainen HO, Honkanen RJ, Saarikoski SV. Bone mineral density in perimenopausal women with asthma: a population-based cross-sectional study. Am J Respir Crit Care Med. 1999;159:1179-85.

19. Appleton SL, Wilson DH, Tucker G, Ruffin RE, Taylor AW, Adams $\mathrm{RJ}$, et al. Sex differences in asthma morbidity associated with obesity in a representative population sample. J Allergy Clin Immunol. 2008 May;121(5):1285-1287.e1.

20. Mazess RB, Barden HS, Drinka PJ, Bauwens SF, Orwoll ES, Bell NH. Influence of age and body weight on spine and femur bone mineral density in U.S. white men. J Bone Miner Res. 1990;5:645-52.

21. Baumgartner RN, Stauber PM, Koehler KM, Romero L, Garry PJ. Associations of fat and muscle masses with bone mineral in elderly men and women. Am J Clin Nutr. 1996;63:365-72.

22. Herrala j, Puolijoki H, Impivaara O, Liippo K, Tala E, Nieminen MM. Bone mineral density in asthmatic women on high -dose inhaled beclomethasone dipropionate. Bone. 1994;15:621-3.
23. Elmstahl S, Ekstrom H, Galvard H, Johnell O, Gerhardsson de Verdier $\mathrm{M}$, et al. Is there an association between inhaled corticosteroids and bone density in postmenopausal women? J Allergy Clin Immunol. 2003;111:91-6.

24. Wong Ca, Walsh Lj,Smith Cj , Wisniewski AF, Lewis SA, Hubbard R, et al. Inhaled corticosteroid use and bone-mineral density in patients with asthma. Lancet. 2000,22;355(9213):1399-403.

25. Hanania NA, Chapman KR, Sturtridge WC, Szalai JP, Kesten S. Doserelated decrease in bone density among asthmatic patients treated with inhaled corticosteroids. J Allergy Clin Immunol. 1995;96(5 Pt 1):5719.

26. Fujita K, Kasayama S, Hashimoto J, Nagasaka Y, Nakano N, Morimoto $\mathrm{Y}$, et al. Inhaled corticosteroids reduce bone mineral density in early postmenopausal but not premenopausal asthmatic women. J Bone Miner Res. 2001;16(4):782-7.

27. Tattersfield AE, Harrison TW, Hubbard RB, Mortimer K. Safety of inhaled corticosteroids. Proc Am Thorac Soc. 2004;1:171-5. 